\title{
ANCESTRAL STATE RECONSTRUCTION OF MIGRATION: MULTISTATE ANALYSIS REVEALS RAPID CHANGES IN NEW WORLD ORIOLES (ICTERUS SPP.)
}

\author{
Beatrice Kondo and Kevin E. Omland ${ }^{1}$ \\ Department of Biological Sciences, University of Maryland-Baltimore County, 1000 Hilltop Circle, Baltimore, \\ Maryland 21250, USA
}

Aвstract.-During the past century, numerous theoretical articles explored the evolution of seasonal migration in birds; many of these focused on environmental or social conditions that may have led to the origin of migration. More recent work has focused not on the origin of migration, but on changes in migratory behavior that have occurred in modern species and their immediate ancestors. We used a novel approach, a multistate ancestral state reconstruction of migration, to examine patterns of migratory evolution in the New World orioles (Icterus spp.). Both the multistate and binary reconstructions indicated repeated gains in migration. However, the multistate method revealed details of how migration may be gained that the standard binary-state reconstructions would not have shown. Our maximum-likelihood reconstruction, using branch lengths based on a molecular phylogeny, suggested multiple instances of rapid gain of migration. Furthermore, we found that every migratory species' migration type differed from that of its closest relatives. Surprisingly, no partially migratory species was closely related to a fully migratory species. These novel patterns involving gain of migration demonstrate the utility of multistate ancestral reconstruction for examining changes in migratory behavior in closely related birds. Received 2 September 2005, accepted 20 March 2006.

Key words: ancestral state reconstruction, evolution of migration, Icterus, multistate reconstruction, New World orioles.

Reconstrucción de Estados Ancestrales de la Migración: Análisis con Múltiples Estados de Carácter Revelan Cambios Rápidos en los Orioles del Nuevo Mundo (Icterus spp.)

Resumen.-Durante el siglo pasado, numerosos artículos teóricos exploraron la evolución de la migración estacional en las aves. Muchos de éstos se enfocaron en las condiciones ambientales o sociales que podrían haber conducido al origen de la migración. Los trabajos más recientes no se han enfocado en el origen de la migración, sino en los cambios en el comportamiento migratorio que sucedieron en las especies modernas y sus ancestros inmediatos. En este estudio empleamos un enfoque novedoso, una reconstrucción ancestral de la migración basada en múltiples estados de carácter, para examinar los patrones de evolución de la migración en los orioles del nuevo mundo (Icterus spp.). Tanto las reconstrucciones con múltiples estados como las reconstrucciones binarias indicaron que la migración ha aparecido repetidamente. Sin embargo, el método con múltiples estados reveló detalles acerca de cómo podría haberse adquirido la migración que las reconstrucciones binarias estándar no hubieran mostrado. Nuestra reconstrucción de máxima verosimilitud realizada con base en la longitud de ramas en una filogenia molecular sugirió varias instancias de adquisición rápida de la migración. Además, encontramos que el tipo de migración

\footnotetext{
${ }^{1}$ Address correspondence to this author. E-mail: omland@umbc.edu
} 
realizado por cada especie migratoria difirió del de los taxones más cercanamente emparentados. Sorprendentemente, ninguna especie parcialmente migratoria está estrechamente emparentada con una completamente migratoria. Estos patrones novedosos que involucran la adquisición de la migración demuestran la utilidad de la reconstrucción ancestral con múltiples estados de carácter para examinar los cambios en el comportamiento migratorio en aves cercanamente emparentadas.

THE EVOLUTION OF avian migration has engendered numerous, often contradictory theories about its origin. Mayr and Meise (1930) discussed the importance of seasonal wanderers and facultative partial migrants to investigations of migration. They encouraged "an investigation of the transitions between sedentary, facultative partial migrant, and migratory birds" (translated from the German; Mayr and Meise 1930:152) as an important means of understanding the evolution of migration. Cox (1985) also posited a transition from purely sedentary species through partial migrants to shortdistance and eventually long-distance migrants. He reasoned that certain biogeographical circumstances (such as, but not limited to, those on the Mexican Plateau and stretching into the deserts of the southwestern United States) were conducive to the instigation of partial migration. Lacking a phylogenetic means to examine gains and losses of migration, he could not provide examples of species that had transitioned from sedentariness through partial migration to increasing migratory distances as described in his model. Another perspective on this issue was introduced by Chesser and Levey (1998), who suggested a tropical edge or canopy habitat as conducive to the development of migration, demonstrating on a multifamily phylogeny that migration was gained independently in several of the edge- or canopy-dwelling taxa, whereas it was never gained in forest-interior-dwelling taxa. They urged the further investigation of this phenomenon at lower phylogenetic levels.

Examination of ancestral gains and losses of migration requires a phylogenetic approach to avoid certain incorrect conclusions about ancestral states (e.g., Zink 2002, Blue-gray Gnatcatcher [Polioptila caerulea]). Because some species have changed their migratory behavior rapidly (e.g., Mayr 1926, Rappole 1995, Able and Belthoff 1998, Sutherland 1998), this phylogenetic approach should be applied across multiple closely related taxa within a genus. As Zink (2002) elucidated, the ultimate origin of migration early in avian history (or even pre-avian history) remains obscure and cannot be examined phylogenetically at this time. However, ancestral state reconstruction can provide valuable insights when applied to recently evolved taxa. Previous ancestral state reconstructions of migration (Chesser and Levey 1998, Cicero and Johnson 2002) have urged examination of migratory behavior at lower levels, even the intraspecific level (see Joseph et al. 2003). Joseph et al. (1999) urge caution in reconstructing migration because of its lability, and Zink (2002) warns against the use of ancestral state reconstructions at deeper phylogenetic levels. Thus, phylogenies might more properly be employed for examining recent changes-both gains and losses - in migratory behavior, rather than for determining ancestral states of migration in the more distant evolutionary past.

Phylogenies to be used for reconstructing ancestral migratory states should be created using techniques that allow the estimation of branch lengths, which indicate the amount of divergence for each taxon (Schluter et al. 1997, Omland 1999, Pagel 1999). Additionally, the ancestral states should be reconstructed using multiple methods, including maximum likelihood, which allows the incorporation of branch lengths into the calculations (MESQUITE; Maddison and Maddison 2004). Finally, it is useful to assess the timing of gains and losses in migration, using a molecular phylogeny along with molecular-clock calibrations (Fleischer et al. 1998). Rapid gains and losses of migration in some species (gains: Rappole 1995, Able and Belthoff 1998, Berthold 1999; losses: Mayr 1926, Klein and Brown 1994, Omland 1997) indicate that ancestral state reconstruction should use dense taxon-sampling (i.e., sampling multiple subspecies, sensu Omland et al. 1999), to avoid omission of changes that may have occurred between subspecies.

Previous phylogenetic studies reconstructed migration as a binary character, coding species as either migratory or nonmigratory (Burns 
1998; Chesser and Levey 1998; Cicero and Johnson 1998, 2002; Joseph et al. 1999, 2003; Chesser 2000; Outlaw et al. 2003; but see Outlaw and Voelker 2006). Because migration may transition from sedentary ancestors through partial migrants to increasingly longer-distance migrants or vice versa (Mayr 1926; Mayr and Meise 1930; Cox 1968, 1985), we treat migration as a multistate character. If partial migration is the ancestral state, and both year-round residency and obligate migration are derived from that state (Berthold 1999), the inclusion of partial migration as a character state is crucial to a thorough analysis of transitions between migratory states. Because the term "partial migration" has several definitions (Terrill and Able 1988), we will specify which form(s) of partial migration we observe in New World orioles (Icteridae: Icterus spp.).

New World orioles include species and subspecies that exhibit a diversity of movement behaviors: sedentariness, partial migration, and short- and long-distance migration. Furthermore, this genus is speciose, containing more than two dozen species, many of which include two or more named subspecies (Jaramillo and Burke 1999). We examined changes in New World oriole migration using a phylogeny based on mitochondrial DNA (mtDNA; Omland et al. 1999) that has been supported in its deeper subdivisions using nuclear intron data (Allen and Omland 2003). To reconstruct ancestral states of migration, we used parsimony-based and likelihood-based methods. New World orioles are an excellent model system for reconstructing changes of migration, not only because of the number of species and subspecies in this genus, but also because several closely related pairs among these taxa (Omland et al. 1999, Baker et al. 2003, Kondo et al. 2004) exhibit different migratory characteristics. Hence, New World orioles allow the examination of migratory changes that have occurred over short evolutionary time frames.

In the present study, we reconstructed ancestral states of migration among 45 taxa in the genus, including many subspecies and all recognized species, examining migration as a character with several possible states. To our knowledge, this study and Outlaw and Voelker's (2006) are the first to employ a multistate approach to the reconstruction of gains and losses in migration. Our goal was to use this densely sampled, taxon-rich genus to examine the timing and directionality of historical increases and decreases in migration. This study of the evolution of migration will contribute to a general understanding of how species transition between different migratory behaviors.

\section{Methods}

Determination of migratory behavior. -We determined the migratory status of New World oriole species and subspecies from examination of the following sources: Howell and Webb (1995), Jaramillo and Burke (1999), and Birds of North America species accounts (Scharf and Kren 1996, Rising and Flood 1998, Rising and Williams 1999, Pleasants and Albano 2001, Flood 2002, Flood et al. 2002). Behaviors were classified as long-distance migration, shortdistance migration, partial migration, and sedentariness. Migratory distances for each species were defined as the distance, in degrees of latitude, between the midpoints of breeding and wintering ranges (data not shown). Species with $<10$ degrees difference between the midpoints of their breeding and wintering ranges were classified as short-distance migrants; species with $>15$ degrees difference were classified as long-distance migrants (there were no species with 10-15 degrees difference). Partial migrants were defined as taxa in which some individuals were obligate migrants and other individuals were sedentary (see Terrill and Able 1988). Taxa that did not exhibit any of these types of movement were classified as sedentary. For the binary ancestral state reconstruction, longdistance, short-distance, and partial migrants were all classified as migratory; sedentary taxa were classified as nonmigratory. We refer to this group of behaviors, including "sedentariness," as "movement behaviors."

Ancestral state reconstruction: Parsimony and maximum likelihood.-We imported the published mtDNA phylogeny of New World orioles (figure 7 in Omland et al. 1999) into MACCLADE (Maddison and Maddison 2000). We then added the taxa Icterus auricapillus and I. dominicensis dominicensis, on the basis of their positions in figure 4a in Omland et al. (1999). We mapped each character type separately onto the tree, and evaluated ancestral states using equally weighted unordered parsimony.

Maximum-likelihood reconstructions use information about amounts of genetic divergence 
between taxa in calculating ancestral states. To provide this information, we imported the phylogenetic tree of New World orioles containing branch lengths (Omland et al. 1999, figure 7) into MESQUITE (Maddison and Maddison 2004). (Icterus auricapillus and I. dominicensis dominicensis were not included because the lengths of the branches leading to them were not available.) Ancestral states were reconstructed using the Markov k-state one-parameter model (Mk1). The Mk1 model assumes equal rates of change between any of the character states. MESQUITE estimated rates of change based on the input data.

\section{Results}

The binary reconstruction based on parsimony (Fig. 1) suggested five independent gains of migration (changes from a nonmigratory ancestor to a migratory descendent). Three of those gains were on branches leading to pairs of extant taxa that were both migratory: (1) I. spurius spurius and I. s. fuertesi, (2) I. bullockii bullockii and I. b. parvus, and (3) I. galbula and I. abeillei. Of the $45 \mathrm{New}$ World oriole taxa examined in the molecular phylogeny (Omland et al. 1999), 8 were migratory and 37 were nonmigratory. Both larger clades (clades A and C) contained migratory and nonmigratory taxa, whereas the smaller clade (clade B) contained only nonmigratory taxa.

The multistate reconstruction using unordered parsimony (Fig. 2A) suggested five gains of migration, as well as three changes that could be gains or losses. The three equivocal changes were within the three pairs of extant taxa that were both migratory; three unequivocal gains

Clade A

Clade B

Clade C

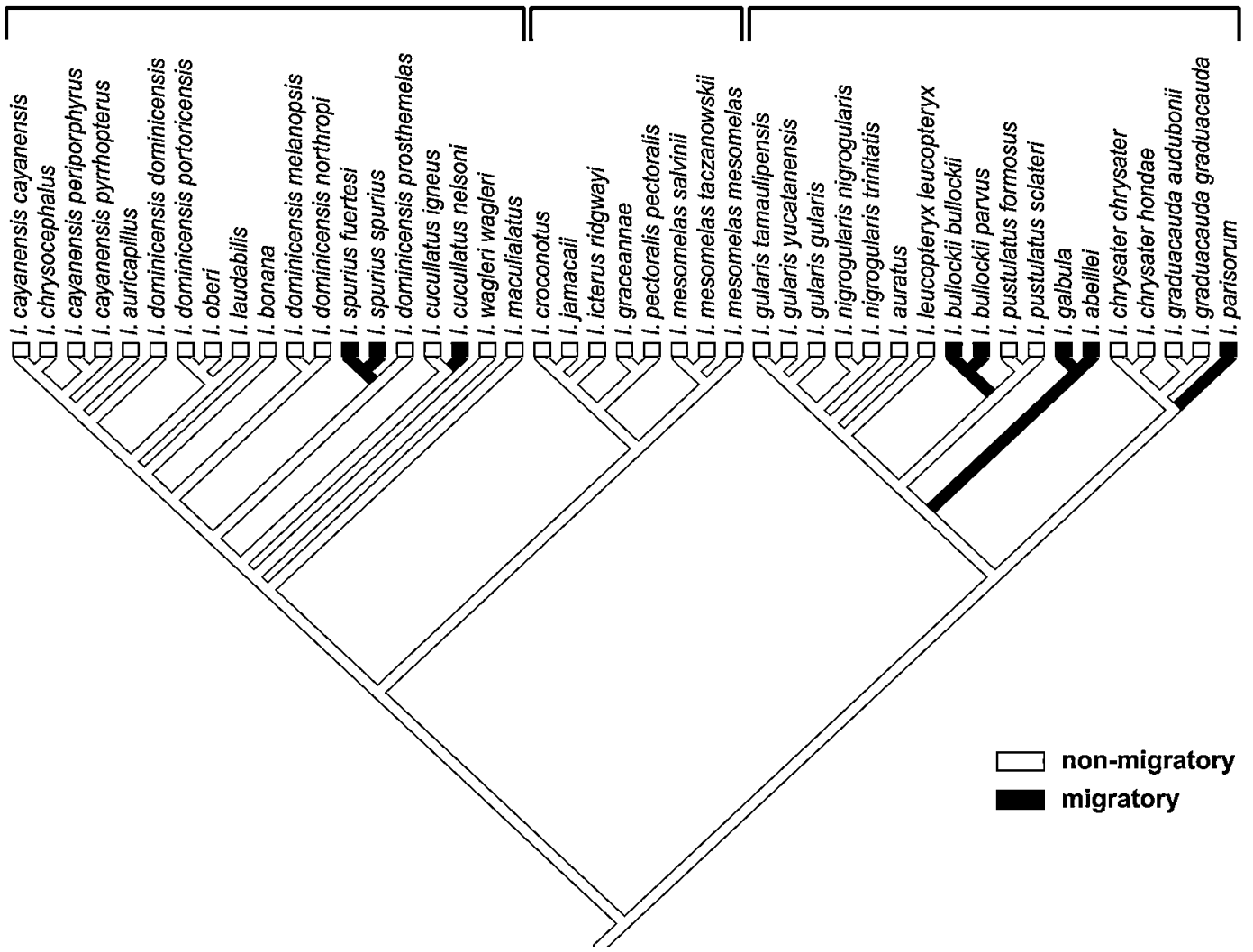

FIG. 1. Parsimony reconstruction of migration as a binary character in New World orioles. This reconstruction suggests five independent gains of migration, and no losses. There are three pairs of sister taxa displaying the same migratory behavior. 
Clade A

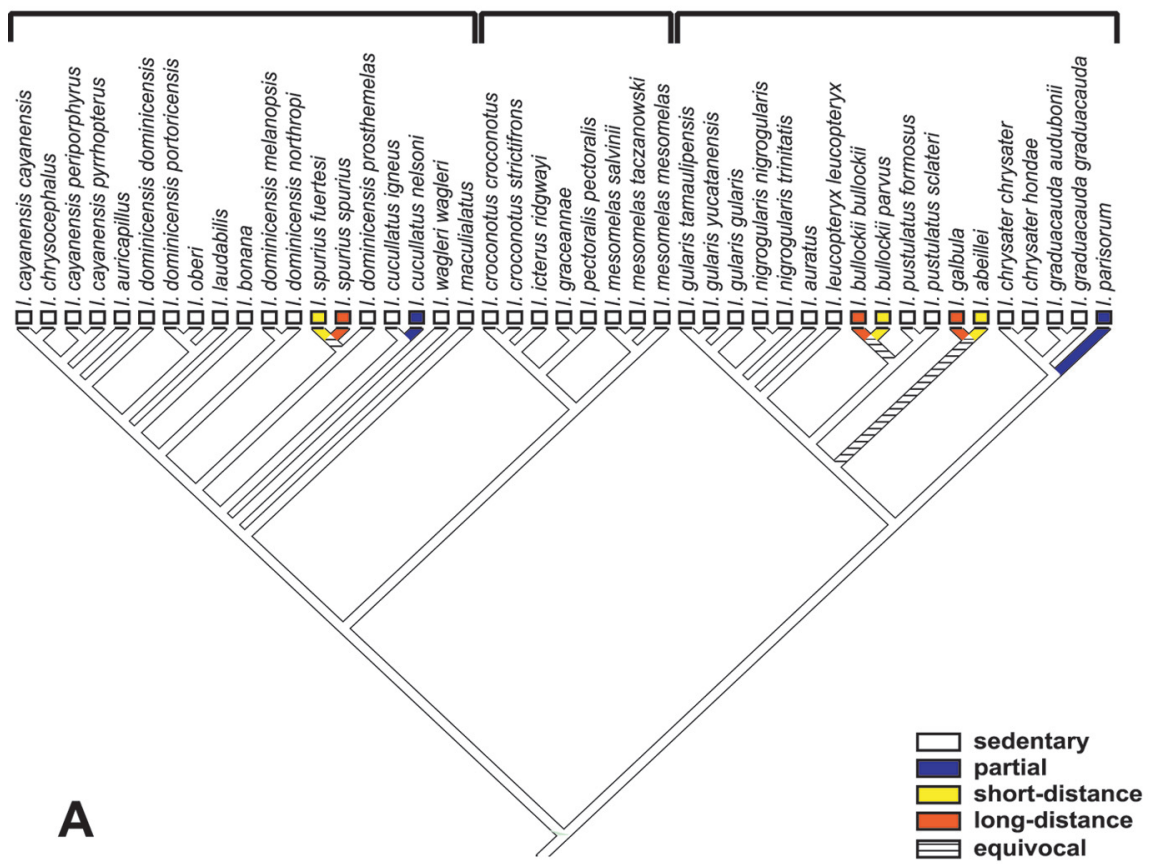

Clade A

Clade B

Clade C

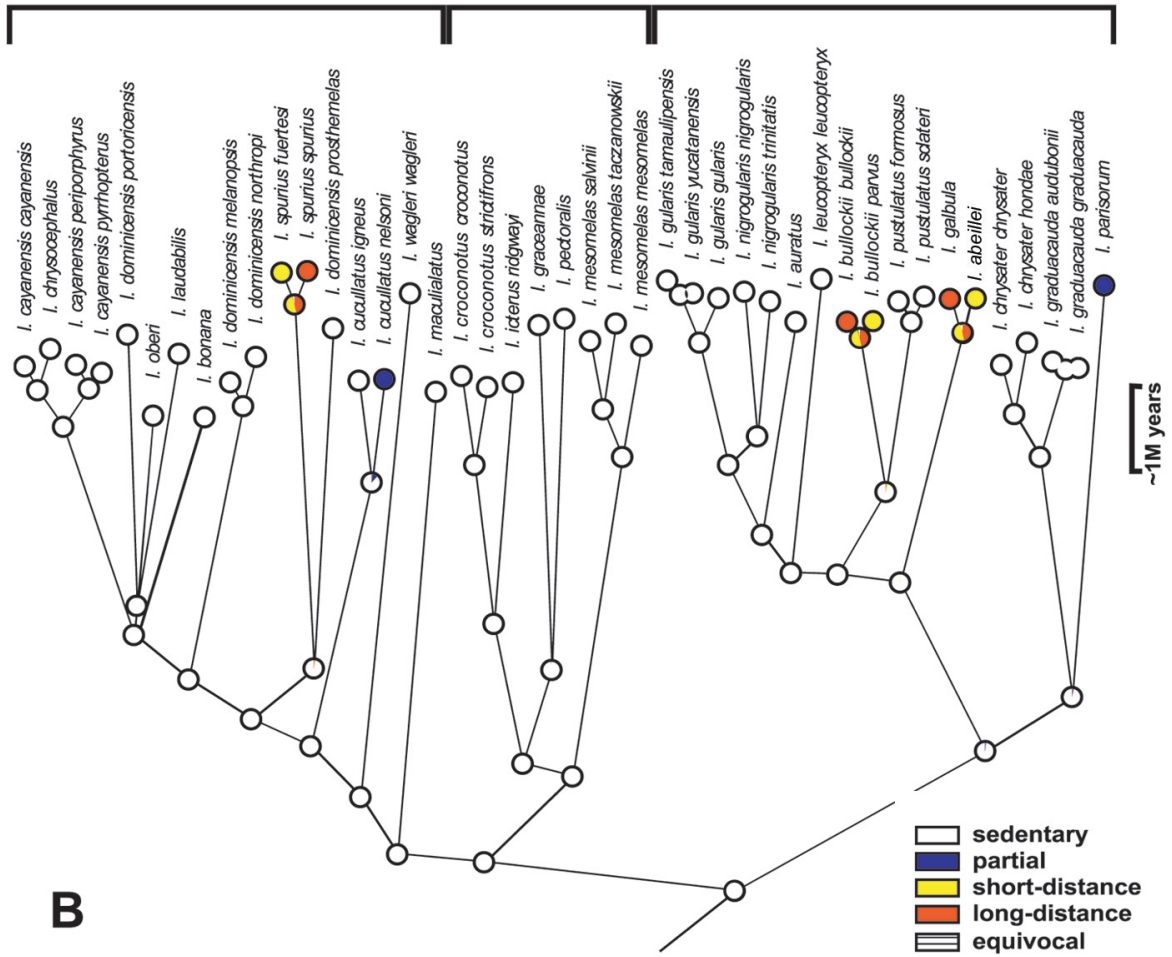


were in the branches leading to the common ancestors of each of those pairs. Of the eight migratory taxa, three were long-distance migrants (I. s. spurius, I. bullockii, and I. galbula). The other five taxa were short-distance migrants, three of them fully migratory (I. $s$. fuertes, I. b. parous, and I. abeillei), and two of them obligate partial migrants (I. cucullatus nelsoni and I. parisorum). The partial migrants were both migratory in the northern parts of their ranges, and sedentary farther south, thus conforming to Cox's (1985) usage of the term.

The maximum-likelihood multistate reconstruction (Fig. 2B) also suggested that there had been repeated gains of migration. The same five clades show gains in migratory behavior. Focusing on the branch lengths, every longdistance migrant had a single closely related sister-taxon that was a short-distance migrant. Of the two obligate partial migrants, I. c. nelsoni was closely related to the sedentary $I$. $c$. igneus, whereas I. parisorum had no extant close relatives.

Across all analyses, there were three large clades of sedentary species. The sedentary species included all the insular and South American taxa, as well as many of the Central American taxa. One of the sedentary clades was the entire clade B; clades A and C also each contained a sedentary clade.

\section{Discussion}

Rapid changes in migratory behavior. - All three analysis methods were highly congruent: New World orioles exhibit multiple rapid gains in migration. Regardless of reconstruction method, there are at least five recent gains in migration within this genus (Figs. 1 and 2). Both multistate reconstructions (Fig. 2) suggest three additional recent changes, in the branches leading to the three long-distance-short-distance migratory pairs. Furthermore, the maximum-likelihood reconstruction, which uses branch lengths to indicate relatedness (Fig. 2B), indicates that these three additional changes occurred between very closely related taxa. Previous studies indicated that these taxon pairs likely diverged within the late Pleistocene, and perhaps as recently as during the Wisconsin glaciations (Omland et al. 1999, Baker et al. 2003, Kondo et al. 2004). The partially migratory taxa diverged from their most closely related extant relatives somewhat earlier, likely within the early Pleistocene (I. c. nelsoni) or the Pliocene (I. parisorum) (Omland et al. 1999).

The three additional changes suggested by multistate analyses are instances in which migration may have recently increased or decreased. The common ancestor of each long-distance-short-distance migratory pair is reconstructed equivocally as either a shortdistance or a long-distance migrant. If it was short-distance, migration increased rapidly in the branch leading to the long-distance migrant. If the common ancestor was a long-distance migrant, then migration decreased rapidly in the branch leading to the short-distance migrant. Further phylogenetic examinations of migration should examine other speciose genera at the lowest levels possible, to determine whether there are less ambiguous examples of rapid decreases in migration.

The rapid changes in migration we observed support the utility of reconstructing ancestral migratory behavior on a subspecies-level phylogeny (also see Joseph et al. 2003). Previous phylogenetic studies at higher levels (i.e., multifamily or multigenus) have stressed the importance of conducting further studies at lower levels, such as at the species or subspecies level (Chesser and Levey 1998, Cicero and Johnson 2002). Our study supports this perspective, given that we found several instances in which sister subspecies exhibited different behaviors (Fig. 2B). In fact, the only sister species or subspecies

Fig. 2. (Previous page) Reconstructions of migration as a multistate character in New World orioles. (A) Parsimony reconstruction, assuming unordered change between character states. This reconstruction suggests five gains of migration, as well as three changes that could be gains or losses (in the three closely related long-distance-short-distance pairs). All branches marked as "equivocal" were equivocal between "short-distance" and "long-distance." (B) Maximum-likelihood reconstruction, assuming equal rates of change between character states. This reconstruction also suggests five gains of migration, as well as three changes that could be gains or losses (in the three closely related long-distance-short-distance pairs). 
exhibiting the same behaviors were the completely sedentary taxa. When sister subspecies exhibit different migratory behaviors, one or both of them must have changed behaviors since the time they diverged from their common ancestor. Our study demonstrates that in multiple instances, New World oriole taxa have changed their migratory behaviors within the divergence time of many recognized subspecies pairs. Further phylogenetic studies of migration should sample as many subspecies, geographic areas, and migratory types as possible, to avoid losing valuable data from subspecies with different behaviors. Migration is clearly too labile to assess gains and losses by sampling only at higher taxonomic levels.

Multistate analysis of migration.-Comparing the parsimony-reconstruction of migration as a binary character (Fig. 1) to the parsimonyreconstruction of migration as a multistate character (Fig. 2A) demonstrates the loss of information that may occur when using binary analyses for characters that have more than two states (also see Hibbett 2004). The three pairs of long-distance and short-distance migrants are simply represented as three pairs of migrants in the binary analysis. Migration thus appears to be less labile, because there are several pairs of closely related taxa with the same behavior.

Using multistate reconstruction, we observed the following paired behaviors among closely related taxa: long-distance migration-shortdistance migration, partial migrationsedentariness, and sedentariness-sedentariness. Interestingly, we did not observe any shortdistance migration-partial migration pairs. No migratory taxon has a close relative with the same behavior. By contrast, there are three large clades of sedentary species that do not exhibit evidence of any change in migratory behavior (Fig. 2B).

Comparison with previous studies. - All longdistance migrant New World orioles are most closely related to short-distance migrants that breed and winter in Mexico or California. The long-distance migrants breed north of the breeding ranges of their short-distance-migrant sister taxa, and winter south of the wintering ranges of their sister taxa, in a "leapfrog" pattern of migration. This is an interesting exemplification of Cox's (1985) Mexican Plateau theory of the origin of migration. Cox predicted that partial migration would arise from sedentary populations in these areas. Eventually, partial migration would displace sedentariness, only to be displaced, in turn, by full migration. Cox's suggestion that partial migration is an intermediate state in the transition from sedentary to fully migratory, and that partial migration disappears when fully migratory populations are established, may explain why we observed no partial-migrant-short-distance migrant taxon pairs, whereas we observed both sedentary-partial-migrant pairs and shortdistance-long-distance migrant pairs (both of which Cox predicted). Furthermore, the large clades of sedentary taxa we observed are insular or South American, which also supports Cox's Mexican Plateau theory.

Our results differ strongly from those of three previous phylogenetic studies of NearcticNeotropic migrants (Burns 1998; Cicero and Johnson 1998, 2002; also see Outlaw et al. 2003). These studies demonstrated phylogenetic conservatism of migration (i.e., contained clades composed entirely or almost entirely of migratory species). Multiple closely related migratory species could indicate that migration in Nearctic-Neotropic migrants is a "key innovation" (sensu Winker 2000) leading to increased speciation along migratory lineages. It would be interesting to determine whether a multistate approach would affect the phylogenetic conservatism observed in these studies.

In New World orioles, long-distance migrants are Neartic-Neotropic; there are no austral migrants (birds breeding in South America and migrating north to their wintering ranges) in this genus. Nevertheless, our results are more similar to those found in studies of austral migration (Chesser 2000, Joseph et al. 2003; also see Chesser and Levey 1998) that reconstructed multiple recent gains of migration. Chesser (2000) suggested that austral migrant taxa would display multiple recent gains in migration, whereas Nearctic-Neotropic migrants would display earlier gains with many migratory descendents. New World orioles provide an interesting contrast to Chesser's prediction and previous studies of migration.

These and other previous phylogenetic-based reconstructions of ancestral migratory behavior mostly reconstructed a nonmigratory ancestor (parsimony reconstruction: Burns 1998; Chesser and Levey 1998; Cicero and Johnson 1998, 2002; Joseph et al. 2003; Outlaw et al. 2003) or an equivocal ancestor (maximum-likelihood 
reconstruction: Joseph et al. 1999, Chesser 2000, Outlaw et al. 2003). We are aware of only one study (Klein and Brown 1994) that reconstructed a migratory ancestor; however, that study showed that a tree consistent with a nonmigratory ancestor was only one step longer than the shortest (see Omland 1997). These results are in accord with our reconstructions, but again, we caution against placing too much credence in ancestral states for deeper nodes in any tree that reconstructs a labile character.

Summary. - Both binary and multistate analyses of migration demonstrate multiple independent gains of migration. However, the multistate analysis also suggests a more rapid gain of migration, with changes occurring as recently as the divergence time between sister subspecies. Furthermore, the multistate analyses indicate that closely related migratory taxa do not share the same behavior. Long-distance migrants are always paired with short-distance migrants. The inability of long-distance migrants with a large contiguous breeding range to develop disjunct breeding populations within that range may hinder speciation. Only when the ancestral population's breeding range has become disjunct is it possible for speciation to occur (see Winker 2000). Although this could explain the absence of pairs of closely related long-distance migrants (or pairs of closely related short-distance migrants), it does not explain why each long-distance migrant New World oriole has a "leapfrog" pattern of migration that brackets the range of the closely related short-distance migrant (Howell and Webb 1995, Jaramillo and Burke 1999). Additional investigation into environmental circumstances affecting these long-distance-short-distance pairs may elucidate the origin of this interesting pattern. Multistate examinations of other speciose genera with varying migratory characteristics are needed to determine whether the patterns observed in New World orioles are unique or more general. Finally, we are now conducting detailed population-genetic analyses of the closely related long-distance-short-distance migratory taxon pairs to better understand the recent migratory changes in the New World orioles.

\section{Acknowledgments}

We thank J. L. Peters and G. H. Huber for valuable discussions and comments on the manuscript. Three anonymous reviewers also provided helpful advice and encouragement. E. H. Humphries proofread multiple versions of the manuscript. W. Maddison and D. Maddison provided virtually instantaneous technical support with MESQUITE. K. E. Omland is supported by National Science Foundation grant DEB-0347083.

\section{Literature Cited}

Able, K. P., and J. R. Belthoff. 1998. Rapid 'evolution' of migratory behaviour in the introduced House Finch of eastern North America. Proceedings of the Royal Society of London, Series B 265:2063-2071.

Allen, E. S., and K. E. Omland. 2003. Novel intron phylogeny supports plumage convergence in orioles (Icterus). Auk 120:961-969.

Baker, J. M., E. López-Medrano, A. G. Navarro-Sigüenza, O. R. Rojas-Soto, and K. E. OmLand. 2003. Recent speciation in the Orchard Oriole group: Divergence of Icterus spurius spurius and Icterus spurius fuertesi. Auk 120:848-859.

Berthold, P. 1999. A comprehensive theory for the evolution, control and adaptability of avian migration. Ostrich 70:1-11.

Burns, K. J. 1998. Molecular phylogenetics of the genus Piranga: Implications for biogeography and the evolution of morphology and behavior. Auk 115:621-634.

Chesser, R. T. 2000. Evolution in the high Andes: The phylogenetics of Muscisaxicola Ground-Tyrants. Molecular Phylogenetics and Evolution 15:369-380.

Chesser, R. T., and D. J. Levey. 1998. Austral migrants and the evolution of migration in New World birds: Diet, habitat, and migration revisited. American Naturalist 152: 311-319.

Cicero, C., and N. K. Johnson. 1998. Molecular phylogeny and ecological diversification in a clade of New World songbirds (genus Vireo). Molecular Ecology 7:1359-1370.

Cicero, C., AND N. K. Johnson. 2002. Phylogeny and character evolution in the Empidonax group of tyrant flycatchers (Aves: Tyrannidae): A test of W. E. Lanyon's hypothesis using mtDNA sequences. Molecular Phylogenetics and Evolution 22:289-302.

Cox, G. W. 1968. The role of competition in the evolution of migration. Evolution 22: 180-192. 
Cox, G. W. 1985. The evolution of avian migration systems between temperate and tropical regions of the New World. American Naturalist 126:451-474.

Cunningham, C. W., K. E. Omland, and T. H. OAKLEY. 1998. Reconstructing ancestral character states: A critical reappraisal. Trends in Ecology and Evolution 13:361-366.

Fleischer, R. C., C. E. McIntosh, and C. L. Tarr. 1998. Evolution on a volcanic conveyor belt: Using phylogeographic reconstructions and K-Ar-based ages of the Hawaiian Islands to estimate molecular evolutionary rates. Molecular Ecology 7:533-545.

FLood, N. J. 2002. Scott's Oriole (Icterus parisorum). In The Birds of North America, no. 608 (A. Poole and F. Gill, Eds.). Birds of North America, Philadelphia.

Flood, N. J., J. D. Rising, And T. Brush. 2002. Audubon's Oriole (Icterus graduacauda). In The Birds of North America, no. 691 (A. Poole and F. Gill, Eds.). Birds of North America, Philadelphia.

Hibвetт, D. S. 2004. Trends in morphological evolution in Homobasidiomycetes inferred using maximum likelihood: A comparison of binary and multistate approaches. Systematic Biology 53:889-903.

Howell, S. N. G., AND S. Weвb. 1995. A Guide to the Birds of Mexico and Northern Central America. Oxford University Press, Oxford, United Kingdom.

JARAmillo, A., AND P. Burke. 1999. New World Blackbirds: The Icterids. Princeton University Press, Princeton, New Jersey.

Joseph, L., E. P. Lessa, AND L. Christidis. 1999. Phylogeny and biogeography in the evolution of migration: Shorebirds of the Charadrius complex. Journal of Biogeography 26:329-342.

Joseph, L., T. Wilke, AND D. Alpers. 2003. Independent evolution of migration on the South American landscape in a longdistance temperate-tropical migratory bird, Swainson's Flycatcher (Myiarchus swainsoni). Journal of Biogeography 30:925-937.

Klein, N. K., AND W. M. Brown. 1994. Intraspecific molecular phylogeny in the Yellow Warbler (Dendroica petechia), and implications for avian biogeography in the West Indies. Evolution 48:1914-1932.

Kondo, B., J. M. BaKer, and K. E. Omland. 2004. Recent speciation between the Baltimore
Oriole and the Black-backed Oriole. Condor 106:674-680.

Maddison, D. R., And W. P. Maddison. 2000. MacClade: Analysis of Phylogeny and Character Evolution, version 4.0. Sinauer Associates, Sunderland, Massachusetts.

Maddison, W. P., And D. R. Maddison. 2004. MESQUITE: A modular system for evolutionary analysis, version 1.05. [Online.] Available at mesquiteproject.org.

Mayr, E. 1926. Die Ausbreitung des Girlitz (Serinus canaria serinus L.). Journal für Ornithologie 74:571-671.

Mayr, E., ANd W. Meise. 1930. Theoretisches zur Geschichte des Vogelzuges. Der Vogelzug 1: 149-172.

Omland, K. E. 1997. Examining two standard assumptions of ancestral reconstructions: Repeated loss of dichromatism in dabbling ducks (Anatini). Evolution 51:1636-1646.

Omland, K. E. 1999. The assumptions and challenges of ancestral state reconstructions. Systematic Biology 48:604-611.

Omland, K. E., S. M. Lanyon, and S. J. Fritz. 1999. A molecular phylogeny of the New World Orioles (Icterus): The importance of dense taxon sampling. Molecular Phylogenetics and Evolution 12:224-239.

Outlaw, D. C., and G. Voelker. 2006. Phylogenetic tests of hypotheses for the evolution of avian migration: A case study using the Motacillidae. Auk 123:455-466

Outlaw, D. C., G. Voelker, B. Mila, and D. J. Girman. 2003. Evolution of long-distance migration in and historical biogeography of Catharus thrushes: A molecular phylogenetic approach. Auk 120:299-310.

PAgel, M. 1999. The maximum likelihood approach to reconstructing ancestral character states of discrete characters on phylogenies. Systematic Biology 48:612-622.

Pleasants, B. Y., And D. J. Albano. 2001. Hooded Oriole (Icterus cucullatus). In The Birds of North America, no. 568 (A. Poole and F. Gill, Eds.). Birds of North America, Philadelphia.

Rappole, J. H. 1995. The Ecology of Migrant Birds: A Neotropical Perspective. Smithsonian Institution Press, Washington, D.C.

Rising, J. D., AND N. J. Flood. 1998. Baltimore Oriole (Icterus galbula). In The Birds of North America, no. 384 (A. Poole and F. Gill, Eds.). Academy of Natural Sciences, Philadelphia, 
and American Ornithologists' Union, Washington, D.C.

Rising, J. D., AND P. L. Williams. 1999. Bullock's Oriole (Icterus bullockii). In The Birds of North America, no. 416 (A. Poole and F. Gill, Eds.). Birds of North America, Philadelphia.

Scharf, W. C., ANd J. Kren. 1996. Orchard Oriole (Icterus spurius). In The Birds of North America, no. 255 (A. Poole and F. Gill, Eds.). Academy of Natural Sciences, Philadelphia, and American Ornithologists' Union, Washington, D.C.

Schluter, D., T. Price, A. Ø. Mooers, and D. Ludwig. 1997. Likelihood of ancestor states in adaptive radiation. Evolution 51: 1699-1711.

Sutherland, W. J. 1998. Evidence for flexibility and constraint in migration systems. Journal of Avian Biology 29:441-446.

Terrill, S. B., and K. P. Able. 1988. Bird migration terminology. Auk 105:205-206.

WinKer, K. 2000. Migration and speciation. Nature 404:36.

ZINK, R. M. 2002. Towards a framework for understanding the evolution of avian migration. Journal of Avian Biology 33:433-436.

Associate Editor: K. P. Johnson 